TEMAS GERADORES

Seção de verbetes 
- A Convenção n. 169 da OIT e a sua aplicabilidade para povos e comunidades tradicionais

Renata Carolina Corrêa Vieira 


\section{A Convenção n. 169 da OlT e a sua aplicabilidade para povos e comunidades tradicionais}

Renata Carolina Corrêa Vieira ${ }^{1}$

A Convenção 169 da OIT (1987) representa, dentro da evolução histórica das políticas indigenistas, uma ruptura com os projetos assimilacionista e integracionista, que vigoraram até meados do século XIX na América Latina desde o seu "encobrimento"2.

Segundo Raquel Yrigoyen Fajardo, um novo "horizonte pluralista" é inaugurado no final do século XX e início do século $X X I$, tendo dois marcos históricos como pilares deste novo cenário: (i) as reformas constitucionais realizadas na América do $\mathrm{Sul}^{3} \mathrm{e}$ (ii) a ratificação da Convenção 169 da OIT. A partir de então, passa-se a reconhecer o caráter plurinacional do Estado/nação, dos povos indígenas e do pluralismo jurídico (FAJARDO, 2006).

1 Mestranda do Programa de Pós-Graduação em Direitos Humanos e Cidadania da Universidade de Brasília - PPGDH/UnB. Especialista em Direito Ambiental pela Universidade da Amazônia - UNAMA. Pesquisadora do grupo de pesquisa O Direito Achado na Rua (CNPq).

2 A expressão "encobrimento" foi utilizada por Dussel em oposição ao termo "descobrimento" utilizada pelos europeus quando chegam na América. Vide: DUSSEL, Enrique D. O encobrimento do outro: a origem do mito da modernidade. Petrópolis: Vozes, 1993.

3 Raquel Fajardo situa as reformas constitucionais da Colômbia (1991), Peru (1993), Bolívia (1994), Equador (1998), Venezuela (1999), que passam a incluir o reconhecimento do caráter pluricultural da Nação/Estado/República, reconhecimento dos povos indígenas, reconhecimento do pluralismo jurídico (direitos indígenas e jurisdição especial/justiça). Em que pesem as reformas constitucionais, ainda há tensões, contradições e deficiências para se abrir perspectiva pluralista. 
A Convenção 169 reconhece de modo expresso a autonomia dos povos indígenas e tribais em controlar suas próprias instituições sociais, políticas e culturais, bem como seu desenvolvimento econômico. A consulta prévia se torna um dos principais direitos garantidos a partir desta virada paradigmática neste novo marco legal, sobretudo, noúltimo ciclo de invasão territorial que, para Raquel Fajardo, foi inaugurado a partir da década de $1980 \mathrm{com}$ as políticas do Consenso de Washington ${ }^{4}$ (FAJARDO, 2014). Nesse último ciclo, inúmeras empresas transnacionais se deslocam para o sul-global com a finalidade de extração de recursos naturais, em parceria com os governos locais, mediante a implantação de megaprojetos, que expropriam o território, a cultura e diversos direitos humanos de povos indígenas e comunidades tradicionais.

O direito à consulta e ao consentimento prévio, livre e informado tem como fundamento os direitos humanos dos povos e comunidades tradicionais e a garantia da sua livre determinação, ou seja, o poder de decidirem livremente sobre seu presente e seu futuro. Desse modo, os Estados devem observar a obrigatoriedade de consultar povos afetados por medidas administrativas e legislativas capazes de alterar seus direitos (GARZÓN, YAMADA, OLIVEIRA, 2016).

Embora o Brasil tenha ratificado a Convenção n. 169, o país continua sendo um violador contumaz no que concerne ao direito da consulta prévia de povos indígenas e comunidades tradicionais. Dentre os desafios de implementação do direito à consulta, temos a própria identificação dos sujeitos deste direito. Maiores dificuldades não encontramos em relação aos povos indígenas e comunidades quilombolas. Estas últimas tiveram sua condição de povos tribais reconhecida pelo governo brasileiro, por meio do Decreto n. $4.887 / 2003^{5}$, que regula-

4 O Consenso de Washington consiste em um arranjo político formulado pelos organismos internacionais em relação aos quais os Estados latino-americanos possuíam dívidas (Banco Mundial, Fundo Monetário Internacional etc), que permitiram que empresas transnacionais retornassem aos países da América Latina para a exploração dos recursos naturais (FAJARDO, 2016, p. 7-8).

5 Segundo o Decreto n. 4887/2003, são consideradas comunidades quilombolas os grupos "étnico-raciais, segundo critérios de auto-atribuição, com trajetória histórica própria, dotados de relações territoriais específicas, com presunção de ancestralidade negra 
menta o artigo 68 do Ato das Disposições Constitucionais Transitórias da Constituição Federal de 1988, e quando o Brasil as incluiu pela primeira vez, em 2008, nos relatórios anuais enviados à Comissão de especialistas na Aplicação de Convenções e Recomendações da OIT (GARZÓN, YAMADA, OLIVEIRA, 2016).

No plano interno, um debate relevante está no campo do direito à consulta prévia aos povos e comunidades tradicionais. O Brasil é um dos países mais sociodiversos do mundo, possuindo inúmeras categorias jurídicas e antropológicas que se autodenominam "povos", "comunidades", "populações" tradicionais, entre outras expressões. A exemplo desses povos e comunidades tradicionais, temos os ribeirinhos, seringueiros, quebradeiras de coco babaçu, caiçaras, gerazeiros, vazanteiros, comunidades de fundo de pasto, ciganos, faxinalenses, apanhadoras de flores etc.

A partir da década de 1980, movimentos sociais intensificam e redimensionam o reconhecimento de seu processo identitário como sujeitos coletivos de direito frente ao avanço das fronteiras agrícolas. Alfredo Wagner Almeida aponta que, diante da necessidade de manutenção das condições de vida preexistentes aos grandes projetos econômicos, novas afirmações étnicas emergem com a finalidade de garantir o efetivo controle de domínios representados por territórios fundamentais para sua identidade (ALMEIDA, 1994).

Para Paul E. Little, as resistências ativas às invasõesforam determinantes para a criação de novas identidades redimensionadas a partir do processo histórico de ocupação das fronteiras do país. Sobre esse processo de etnogênese, explica o autor:

Esses múltiplos, longos e complexos processos resultaram na criação de territórios dos distintosgrupos sociais e mostram como a constituição e a resistência culturais de um grupo social são dois lados de um mesmo processo. Além do mais, o território de um grupo social determinado, incluindo as condu-

relacionada com a resistência à opressão histórica própria, dotados de relações territoriais específicas, com presunção de ancestralidade negra relacionada com a resistência à opressão histórica sofrida. 
tas territoriais que o sustentam, pode mudar ao longo do tempo dependendo das forças históricas que exercem sobre ele. Os constantes processos de miscigenação biológica e sincretismo cultural criaram novas categorias étnicas e raciais que formaram parte importante de novos movimentos [...]. Ao mesmo tempo, os processos de etnocídio sofridos pelas distintas sociedades indígenas muitas vezes deram lugar a novos processos de etnogênese, como atesta tanto o caso abortado dos tapuios (Moreira Neto, 1988), quanto os casos do surgimento dos caboclos (Parker 1985) e da fusão de grupos indígenas no alto rio Negro (Hill 1996) (LITTLE, 2002, p. 5).

Segundo Paul Little, "o conceito de povos tradicionais contém tanto uma dimensão empírica quanto uma dimensão política, de tal modo que as duas dimensões são quase inseparáveis" (LITTLE, 2002, p. 23). Para o autor, o uso da expressão "povos" ao invés de "comunidades" tradicionais, ganharia uma importância mais estratégica nas lutas por justiça social, inclusive para fazer valer direitos que estão prescritos na Convenção 169 da OIT, como por exemplo, o direito à consulta prévia.

A Convenção 169 ao definir povos tribais estabelece que "são grupos cujas condições sociais, culturais e econômicasos distingam de outros setores da coletividade nacional, eque estejam regidos, total ou parcialmente, por seus próprioscostumes ou tradições ou por legislação especial" (artigo 1, 1.a). Estabelece, ainda, que "a consciência de sua identidade indígena ou tribal deveráser considerada como critério fundamental para determinaros grupos aos que se aplicam as disposições da presenteConvenção" (artigo 2).

Por sua vez, o Decreto n. 6.040/2007, que cria o Conselho Nacional de Povos e Comunidades Tradicionais (CNPCT) define povos e comunidades tradicionais como "grupos culturalmente diferenciados e que se reconhecemcomo tais, que possuem formas próprias de organizaçãosocial, que ocupam e usam territórios e recursos naturaiscomo condição para sua reprodução cultural, social, religiosa, ancestral e econômica, utilizando conhecimentos, inovações e práticas gerados e transmitidos pela tradição" (artigo I, II). 
Verifica-se que em ambas as definições, encontram-se os mesmos critérios de autodeterminação e de grupos que mantenham estruturas sociais, culturais e econômicas diferenciadas do restante da totalidade da nação, com costumes e tradições próprias. Nota-se que a expansão das fronteiras agrícolasainda que tenham afetado o modo de vida de muitas comunidades tradicionais, pois uma vez envolvidas nas redes comerciais inerentes ao capitalismo,muitas comunidades passaram a readaptar sua economia a essa nova lógica comercial, como o caso dos seringueiros, porém, continuaram mantendo costumes tradicionais, como, por exemplo, o uso coletivo da terra (LITLE, 2002).

Em que pese uma forte resistência do governo brasileiro em adotar a Convenção 169 da OIT para povos tradicionais, já existem precedentes jurisprudenciais de casos em que a Justiça Federal determinou a obrigação da consulta prévia a comunidades tradicionais que seriam atingidas por política pública ou grandes empreendimentos. Destacam-se os casos em que a Justiça Federal reconheceu a necessidadede consultar os pescadores artesanaispara a elaboração do Plano deManejo do Parque Nacional de Superagui, Estado doParaná. Igualmente, obrigou o Estado do Amazonasa consultar as 19 comunidades ribeirinhas afetadaspelo projeto do Polo Naval (GARZÓN, YAMADA, OLIVEIRA, 2016).

Desse modo, defendemos que o direito à consulta prévia previsto na Convenção 169 da OIT é também direito dos povos e comunidades tradicionais, incluindo-se os mesmos dentro da expressão "povos tribais", considerando a sua condição de grupos culturalmente diferenciados. Por isso, devem ser consultados previamente sempre que uma política pública, uma lei ou a instalação de um empreendimento econômico afetar e/ou colocar em risco seu modo de vida e suas estruturas sociais, culturais e econômicas.

\title{
REFERÊNCIAS
}

\author{
ALMEIDA, A. W. B. 1994. Universalização e localismo: movimentos \\ sociais e crise dos padrões tradicionais de relação política na
}


Amazônia. Em D'INCAO, M. A.; SILVEIRA, I. M. (orgs.), A Amazônia e a crise da modernização. Belém: Museu Paraense Emílio Goeldi,. pp.517-532.

FAJARDO, Raquel Yrigoyen. 2006. HitosdelReconocimientodel pluralismo jurídico y elderecho indígena em laspoliticas indigenistas y el constitucionalismo andino. In: Berraondo (ccord): PueblosIndigenas y derechos humanos. Bilbao: Universidad de Deusto. (p. 537-567)

. 2014. Cuálessonlos ciclos históricos de invasión de los territórios indígenas? Disponível em: https://abcderechosindi genas.lamula.pe/2014/09/28/abc-en-derechos-indigenas/abcdere chosindigenas/. Acesso em: 12/07/2018.

GARZÓN, Biviany Rojas; YAMADA, Erika M. ; OLIVEIRA, Rodrigo. Direito à consulta e consentimento de povos indígenas, quilombolas e comunidades Tradicionais. São Paulo: Rede de Cooperação Amazônica - RCA; Washington, DC :DueProcessof Law Foundation, 2016.

LITTLE, Paul. 2002. Territórios sociais e povos tradicionais no Brasil: por uma antropologia da territorialidade. Série Antropologian 322 (Brasília: DAN/UnB). 